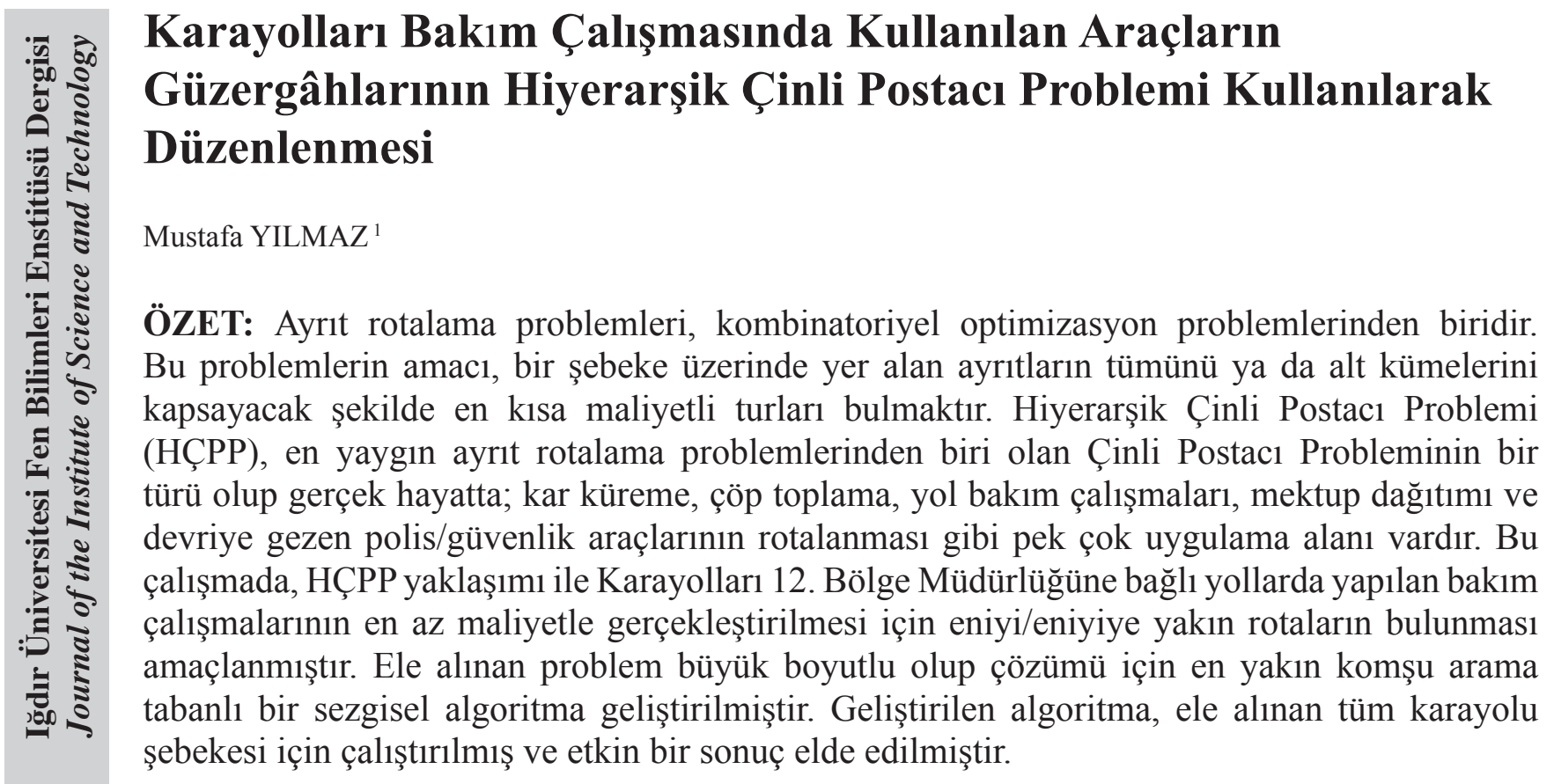

Anahtar Kelimeler: Ayrıt rotalama, hiyerarşik Çinli postacı problemi, karayolu bakım çalışmaları.

\title{
Route Management for Vehicles Used in Road Maintenance Activities through Hierarchical Chinese Postman Problem Approach
}

\begin{abstract}
The arc routing problems are one of the combinatorial optimization problems. The aim of solving such problems is to determine a least cost tour which covers all or subset of arcs in a graph. The Hierarchical Chinese Postman Problem (HCPP) is a variant of Chinese Postman Problem, one of the most common arc routing problems. There are many application areas of HCPP in real life, such as snow plowing, garbage collection, road maintenance, letter delivery, routing of patrolling vehicles. In this study, it was aimed to find the best / nearest routes with the least cost by the HCPP approach in order to carry out the road maintenance activities which the roads connected to the $12^{\text {th }}$ Regional Directorate of Highways. A nearest neighbor search based algorithm was developed in order to solve the handled large-scale problem. The proposed algorithm was conducted on the road network involved and an efficient result was obtained.
\end{abstract}

Keywords: Arc routing, hierarchical Chinese postman problem, road maintenance activities.

Mustafa YILMAZ (0000-0002-2135-5762), Atatürk Üniversitesi, Mühendislik Fakültesi, Endüstri Mühendisliği Bölümü, Erzurum, Türkiye Sorumlu yazar/Corresponding Author: Mustafa YILMAZ, mustafay@atauni.edu.tr 


\section{GİRIŞ}

Rotalama birçok üretim ve servis sektöründe önemli bir karar verme sürecidir. Kamu ve özel işletmelerin bu alanlardaki harcamaları her geçen gün artmakta ve büyük miktarlara ulaşmaktadır. Yetersiz planlamalar ve hatalı yatırımlar neticesinde önemli miktarda kaynak bu alanlarda israf olmaktadir. $\mathrm{Bu}$ nedenle, bu tip problemlerin önemi hızla artmış ve birçok araştırmaya konu olmuştur. Araştırmacıların bu alanlardaki çalışmaları sayesinde daha etkin çözümler bulunmuş, uygulama imkânı artmış ve böylece önemli miktarda tasarrufların sağlanmasına yardımcı olunmuştur (Emel ve ark. 2003)

Rotalama problemleri genel olarak düğüm rotalama ve ayrit rotalama problemleri olmak üzere ikiye ayrilır. Bu problemlerden ilkinde bir şebekenin düğümleri, ikincisinde ise şebekenin ayritları ele alınır. Ayrıt rotalama problemlerinin amacı, bir şebeke üzerinde yer alan tüm ayritlardan en az bir kere geçerek başlangıç düğümüne dönen en kısa rota veya rotaları belirlemektir. Ayrıt rotalama problemlerinden biri Çinli Postacı Problemidir (ÇPP). ÇPP, ilk olarak Çinli bir matematikçi tarafından incelenmiş ve bir postacının postaneden aldığı mektupları mümkün olan en k1sa yoldan şehirdeki tüm sokaklara uğrayarak dağıtmak istemesiyle ortaya çıkmıştır (Kwan, 1962). Mektupların dağıtımından sonra postacı başladığ 1 nokta olan postaneye geri dönmek zorundadır (Ahuja ve ark. 1993). Dolayısıyla bu problem literatürde ÇPP olarak anılmaktadır. ÇPP'nin amacı, verilen bir şebeke üzerindeki ayrıtlardan en az bir kez geçecek şekilde en kısa tur/turların bulunmasıdır. ÇPP; mektupların dağıtımı, çöplerin toplanması, cadde ve otobanlarda kar ve buz kontrolleri, tuzlama, kar temizleme ve sokakların temizlenmesi çalışmaları, okul servisleri ve polis devriye araçlarının rotalanması, su ve gazete dağıtımı, etkili web sitesi kullanılabilirliğinin tespiti gibi birçok alanda kullanılabilmektedir (Thimbleby, 2002). Özellikle, araç rotalarının belirlenmesinde yoğun olarak ÇPP kullanılmaktadır. Zira işletmeler araçlarının çalışma maliyetlerini; araç duraklarını düğüm, yolları da ayrıt olarak ele alan şebeke kuramını kullanarak en küçüklemeye çalışmaktadırlar. Dolayısıyla karayollarında kullanılan araçların, optimum rotalarının belirlenmesi maliyet açısından kaçınılmazdır.

Kar küreme, çöp toplama, tuz serpme ve yol bakım çalışmaları gibi bazı uygulamalarda ise yollar, öncelik ilişkilerine göre kısıtlandırılabilir. Bu problem, literatürde ÇPP'nin bir türü olan Hiyerarşik Çinli Postacı Problemi (HÇPP) olarak adlandırılır. HÇPP'de amaç verilen bir şebekedeki yolların (ayrıtların) öncelik ilişkilerinin dikkate alınarak, yüksek öncelikli yollardan başlanarak düşük öncelikli yollara doğru, şebekedeki her bir ayrıttan en az bir kez geçmek koşuluyla optimum tur/turları bulmaktır (Dror ve ark. 1987).

Literatürde HÇPP ile ilgili çok az sayıda yapılmış çalışma vardır. HÇPP'yi ilk olarak tanımlayan (Dror ve ark. 1987) yaptıkları çalışmada, yolların bölündüğü ve öncelik ilişkilerinin tanımlandığı bir şebekede optimum postacı turunu bulan bir algoritma geliştirmişlerdir. HÇPP'nin NP-zor sınıfinda olduğunu ancak problemin bazı özel durumları için polinomiyal zamanlı algoritmalarla da çözülebileceğini göstermişlerdir. P ve NP kompleks hesaplama teoreminden gelen sinifları ifade etmektedir. Hesaplama teoremine göre P sınıfında yer alan problemler Polynomial zamanda çözülebilecek problemleri ifade etmek için kullanılmaktadır. Yani problemin zorluğu arttı̆̆ında çözüm süresi polinomsal olarak $\left(\mathrm{n}^{2}, \mathrm{n}^{3}\right.$ gibi) artar. Öte yandan, NP sınıfındaki problemlerin çözümü ise NonDeterministic-Polynomial zamanda çözümlenebilir. Problem karmaşıklaştıkça çözüm süresi üssel biçimde $\left(2^{n}, 3^{n}\right.$ gibi) artmaktadır. (Dror ve ark. 1987) yaptıkları çalışmada belirtilen özel durumlar; bütün alt hiyerarşilerin birbirleriyle bağlantılı olduğu ve öncelik ilişkilerinin lineer olduğu durumlardır. Geliştirdikleri algoritma bu bahsedilen özel durumların gerçekleşmemesi halinde sonuç vermemektedir. Lemieux ve Campagna, (1984); Alfa ve Liu, (1988); Krishnamurthi ve Damodaran, (1998) yaptıkları çalışmalarda HÇPP'nin çözümüne yönelik sezgisel algoritmalar geliştirmişlerdir. Alfa ve Liu, (1988) yönlü hiyerarşik bir şebekede daha iyi çözümler veren bir yöntem sunmuşlardır. Ayrıca yaptıkları çalışmada, birbirleriyle bağlantılı olmayan hiyerarşik sınıfları birleştirmek için bağlantısı olmayan hiyerarşik şebekeden yol seçen bir sezgisel yöntem geliştirmişlerdir. Birbirleriyle bağlantısı olmayan alt şebekeleribirleştiren farklı bir sezgisel metot Damodaran (1997) tarafindan sunulmuş olup geliştirilen sezgiselin çözüm performansının daha önceden Alfa ve Liu (1988) tarafından aynı amaç için geliştirilen sezgiselden daha iyi performans sergilediğini göstermiştir.

HÇPP için kesin çözüm veren algoritma ilk kez Ghiani ve Improva (2000) tarafindan oluşturulmuştur. Birtakım varsayımlar altında geliştirdikleri algoritma 
ile önceden geliştirilen yöntemlerden daha kısa süre bilgisayar zamanında çözüme erişilmiştir. Cabral ve ark. (2004) HÇPP'yi, kırsal postacı problemine dönüştürecek bir yöntem önermişlerdir. Öncelik ilişkilerinin lineer olarak ele alındığı problemin çözümü için dal-kesme algoritmasını kullanmışlardır. Korteweg ve Volgenant (2006) öncelik derecelerine göre sınıflandırılmış şebekelerde, öncelik sırasına göre minimum maliyetli rotayı bulan farklı bir algoritma ortaya koymuşlardır. Algoritma ile ilk olarak, en yüksek öncelikli alt şebekenin minimum rotası bulunur. Öncelik sırası göz ardı edilmeksizin her bir alt şebekenin ayrı ayrı minimum maliyetli rotalarının hesaplanmasıyla işlem tamamlanır. Genelde ÇPP'den elde edilen optimum tur çözümü, HÇPP'nin alt sınırı kabul edilmektedir. Damodaran ve ark. (2008) yaptıkları çalışmada, ÇPP'nin çözümleri ile karşılaştırıldığında HÇPP için daha iyi alt sınır değerleri veren bir sezgisel yöntem geliştirmişlerdir. Bu değerlerle kesin arama algoritmaları (dal-sınır gibi) kullanılarak daha kısa zamanda optimum çözüme ulaşıldığını göstermişlerdir. Aynı zamanda geliştirilen sezgisel ile çeşitli problem boyutları ele alınmış ve önceki çalışmalardan daha iyi sonuçlar elde edilmiştir. Sayata ve Desai (2015) yaptıkları çalışmada, Kruskal algoritmasına dayalı minimum yayılan ağaç yaklaşımı kullanarak HÇPP için çözümler elde etmişlerdir.

HÇPP gerçek hayat uygulamalarında oldukça sıklıkla karşımıza çıkmasına rağmen, literatürde sınırlı sayıda çalışma vardır. Yolların önceliklerinin dikkate alındığı durumlardan biri ise karayolları bakım çalışmalarının yapılmasıdır. Türkiye'de kentler arası yol bakım çalışmaları karayolları bölge müdürlükleri tarafından yapılmaktadır. Yol bakım çalışmaları

$$
G=(V, E)=G_{I}\left(V_{1}, E_{1}\right) \cup G_{2}\left(V_{2}, E_{2}\right) \cup \ldots \cup G_{k}\left(V_{k}, E_{k}\right)
$$

Burada $G_{k}, k$. hiyerarşik sınıfa karşılık gelen ayritlardan ve düğümlerden oluşan bir alt şebekedir. Eğer bir hiyerarşik şebekede $p$ seviyesine ait olan yollar $\left(E_{p}\right), q$ seviyesine ait olan yollardan $\left(E_{q}\right)$ yüksek öncelikli ise, HÇPP'nin amacı, $q$ öncelikli yolları için kullanılan farklı özelliklerde çeşitli araçlar bulunmaktadır. Bu araçlardan bir kısmı belirli bölgeleri günlük, haftalık veya aylık periyodik bakımlar yaparken, yılda sadece bir veya iki kere tüm yol ağını dolaşarak kontrol etmek üzere bakım çalışmalarını yapan araçlar da bulunmaktadır. Her bir bakım aracının sorumlu ve bağlı olduğu bir bölge müdürlüğü olmasına rağmen araçların rotaları tamamen sürücünün deneyim ve tecrübesine bağlıdır. Ayrıca yolların bakım işlemleri yapılırken yolların öncelik türüne göre yapılması da ayrı bir önem taşımaktadır. Şöyle ki otoyollar, devlet ve il yolları gibi ana yolların bakım çalışmalarının ilk öncelikli olarak yapılması trafiğin düzenli ve güvenli bir şekilde sürekliliğinin sağlanması açısından büyük önem arz etmektedir. Bu çalışmada, HÇPP yaklaşımı kullanılarak Karayolları 12. Bölge Müdürlügü görev alanındaki yolların bakım işlemlerinin en az maliyetle gerçekleştirilmesi için optimum rotaların bulunması amaçlanmıştır. Ele alınan karayolu ağ şebekesi büyük boyutlu olduğundan çözüm için sezgisel bir algoritma geliştirilmiştir.

\section{MATERYAL VE YÖNTEM}

\section{Hiyerarşik Çinli Postacı Problemi}

Bir hiyerarşik şebeke, farklı öncelik seviyelerine ait ayrıtlardan (yollardan) oluşmaktadır. $G=(V, E)$ şebekesi ele alındığında, $V$, düğümler kümesini, $E$ ise yönsüz ayrıtlar (yollar) kümesini temsil etmektedir. Hiyerarşik bir şebeke, $k$ tane farklı alt-şebekelere bölünür ve her bir alt şebeke bir hiyerarşik seviyeyi temsil eder. Bir hiyerarşik şebeke gösterimi, aşağıda verilen Eşitlik 1. şeklinde ifade edilir.

geçmeden önce $p$ öncelikli yollardaki turu en kısa mesafe ile tamamlamasıdır. Şekil 1'de Korteweg ve Volgenant (2006) tarafından geliştirilen küçük boyutlu bir hiyerarşik şebeke ve her bir hiyerarşik sınıfa ait yollar kümesi verilmiştir. 


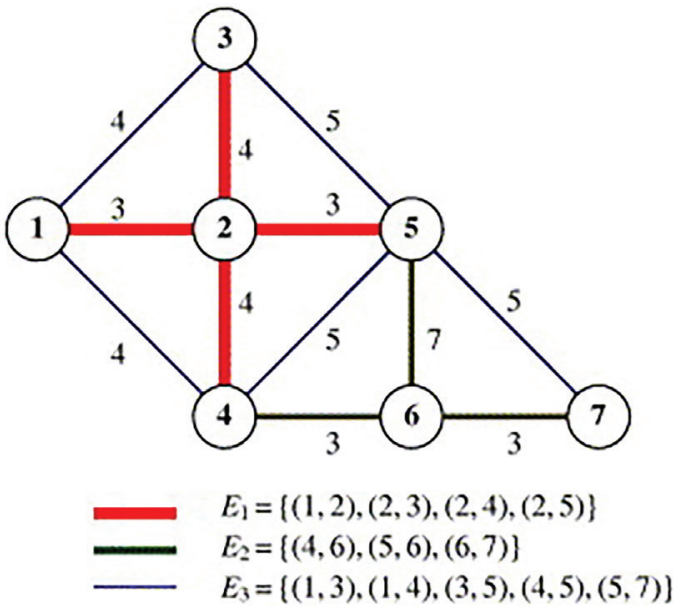

Şekil 1. Hiyerarşik şebeke örneği

Verilen yönsüz şebeke, $V=\{1,2,3,4,5,6,7\}$ düğümler kümesi ve $E=\left\{\begin{array}{l}E_{1} \cup E_{2} \cup E_{3} \\ \}\end{array}\right.$ ayritlar kümesinden oluşmaktadır. Korteweg ve Volgenant (2006) yaptıkları çalışmada, optimum tur mesafesi 67 ve optimum tur, 1-2-3-2-4-2-5-6-4-6-7-5-4-1-3-5-2-1 olarak bulmuşlardır. Şuana kadarki çalışmalarda 2 temel varsayım dikkate alınmıştır. Bunlar;

- Hiyerarşik sınıflar içerisindeki tüm yollar birbirleri ile bağlantılıdır.

- Birbirini takip eden her bir hiyerarşik seviye birbiriyle bağlantılıdır.

HÇPP，NP-zor problem sınıfina aittir (Dror ve ark. 1987). Problemin kombinasyonel yapısı problem boyutu büyüdükçe en iyi sonuçların elde edilmesini güçleştirmektedir. Sonuç olarak problem boyutu arttıkça elde edilen çözüm alternatifleri de artacağından makul zamanda en iyi çözümlere ulaşmak mümkün olamamaktadır. HÇPP; mektup ve posta dağıtımı, polis devriye araçları ve kar temizleme araçlarının rotalanması, otobüs çizelgelenmesi, yol bakım araçlarının rotalanması gibi karşılaşılan pek çok problemin HÇPP'ye uyarlanması ve çözüme gidilmesi gerçek hayat ile örtüşmesi açısından büyük önem arz etmektedir.

\section{Problemin Tanımı}

Türkiye'de ulaştırma türleri arasında karayolu, yolcu ve yük taşımacılığında açık ara önde olan bir türdür. Karayolları son zamanlarda bölünmüş yollara ağırlık verilmesiyle özellikle doğuda vazgeçilmez olmuştur. Mevcut yollara yapılan bu eklemeler veya yeni yüksek standartlı yollar ile birlikte büyük bir ulaşım ağı meydana gelmiştir. $\mathrm{Bu}$ ulaşım ağının büyüklüğünün getirdiği birçok avantajla beraber, hatlarda dolaşan araçların çizelgelenmesi, rotalanması, bakımları vs. gibi çeşitli zorlukları da beraberinde gelmiştir.

Türkiye'de ray bakım için kullanılan farklı özelliklerde çeşitli araçlar bulunmaktadır. Yılmaz ve ark. (2017) yaptıkları çalışmada Türkiye devlet demiryollarında bakım yapan yol ve katener ölçüm aracının rotalanması problemini ele almışlardır. Elde ettikleri sonuç mevcut duruma göre hat üzerinde kat edilen toplam mesafede \% 20.76'lık bir iyileştirme sağlamışlardır. Demiryollarında durum böyleyken kullanım oranı daha yüksek olan karayollarında hiç şüphesiz bakım onarım çok önemli bir yer tutmaktadır. Karayollarında periyodik bakımların yanında şikâyet ve meydana gelen kazalar sonrasında da birtakım bakım ve onarımlar yapılmaktadır. Dolayısıyla tüm hattı dolaşmak suretiyle bakım yapan bu araçların optimum rotasının çıkarılması maliyet ve mesafe açısından kritik bir öneme sahiptir. Çünkü büyük boyutlu ve kompleks şebekeler de kısıtlı sayıda aracın bütün şebekeyi dolaşması için yüzlerce veya binlerce alternatif rota oluşturulabilmektedir. Bu çalışmada yol bakım aracı ile tüm hattın dolaşılıp aracın hiyerarşik kısıtlara uygun olarak optimum rotasının bulunması amaçlanmaktadır.

Şekil 2'de Karayolları 12. Bölge Müdürlüğü görev alanının haritası verilmiştir. Ana yollar, yan yollar ve kavşaklardan oluşan bir karayolu ağı göz önüne alındığında, $G=(V, E)$ genel bir şebekeye dönüştürülebilir. Burada $\mathrm{V}$ düğümler kümesini, $\mathrm{E}$ ayrıtlar kümesini ifade eder. Problemin HÇPP'ye uyarlanarak çözülebilmesi için Karayolları 12. Bölge Müdürlüğü görev alanındaki yollar Şekil 3'te görüldüğü gibi şebeke halinde gösterilmiştir. $\mathrm{G}(\mathrm{V}, \mathrm{E})$ şebekesi, $\mathrm{G}(\mathrm{V}, \mathrm{E})=\mathrm{G}^{1}\left(\mathrm{~V}, \mathrm{E}^{1}\right) \cup \mathrm{G}^{2}\left(\mathrm{~V}^{2} \mathrm{E}^{2}\right)$ iki alt şebekeye bölünmüştür. Genel olarak trafiğin yoğun olduğu devlet yolları, il yolları ve bazı ilçe yolları birinci öncelikli, kalan yollar ise ikinci öncelikli olarak belirlenmiştir. 


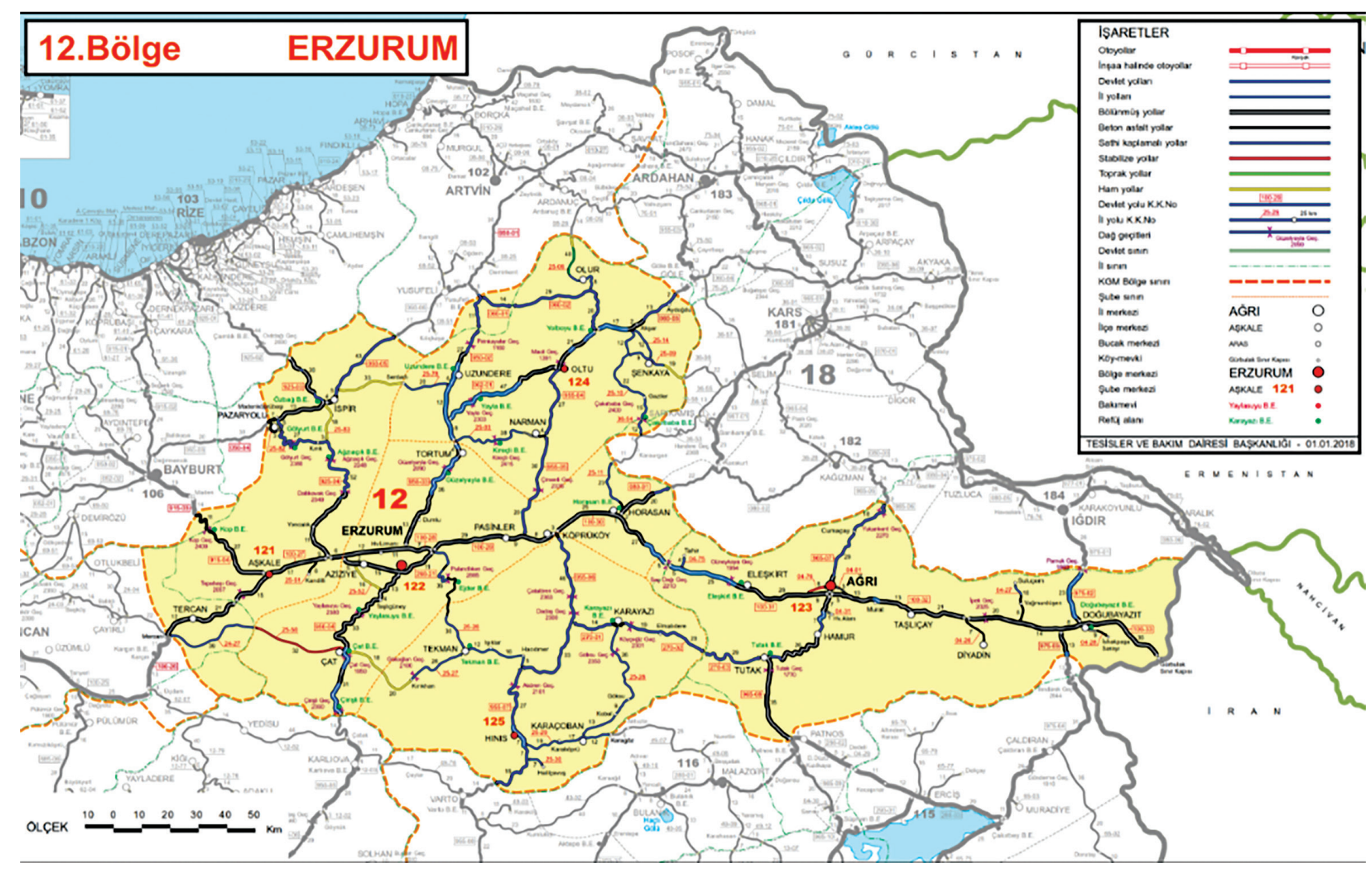

Şekil 2. Karayolları 12. Bölge Müdürlüğü görev alanındaki yolların haritası

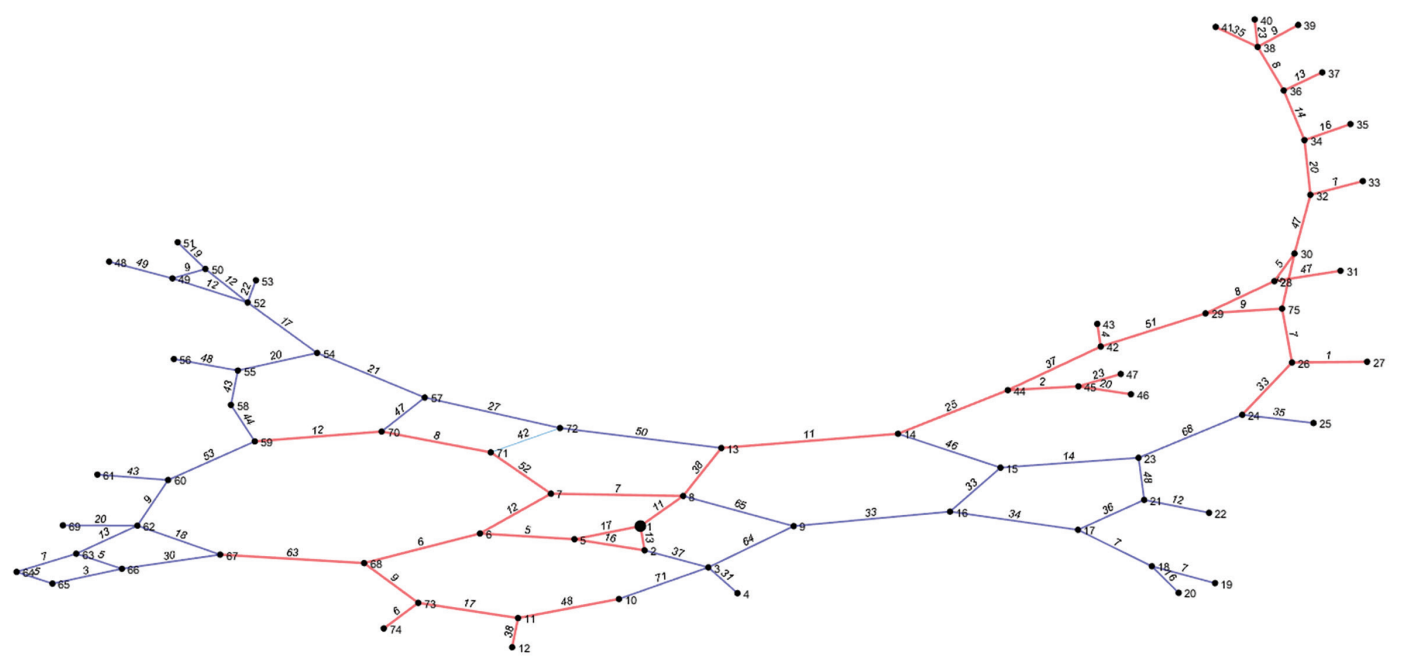

Şekil 3. Karayolları 12. Bölge Müdürlüğ̈̈ görev alanındaki yolların ağ gösterimi

Şekil 3'te görüldüğü üzere yol ağ1 toplam 75 düğümden oluşmaktadır ve düğümler arası mesafeler kilometre olarak verilmiştir.

Kırmızı hatlar birinci öncelikli yolları, maviler ikinci öncelikli yolları temsil etmektedir. 1 numaralı düğüm, bölge merkezi, Erzurum noktasıdır. Aracın başlangıç noktası 1 numaralı düğüm olup araç turunu tamamladıktan sonra tekrar başlangıç noktasına dönmektedir. Tüm yollar iki gidiş iki dönüş olmak üzere bölünmüş nitelikte il yollarıdır. Bölünmüş yollara bağlı bazı kısa mesafeli yollar çok önem taşımamasına rağmen rota akışını bozmaması açısından birinci öncelikli yollar olarak belirlenmiştir (örneğin 34-35 yolu, 42-43 yolu, 38-39 yolu vb.). 


\section{Sezgisel Algoritma}

Çalışmada ele alınan problem büyük boyutlu olduğundan dolayı makul sürede optimum çözüm elde edilememiştir. $\mathrm{Bu}$ nedenle, sonuçlara kabul edilebilir çözümler ile daha hızlı ulaşılması açısından sezgisel bir algoritma geliştirilmiştir.

Geliştirilen algoritma, klasik sezgisel yöntemlerden biri olan En Yakın Komşu Arama Sezgiseli(EYKAS) tabanlı bir algoritmadır. EYKAS ilk olarak Clark ve Evans (1954) tarafindan geliştirilmiş ve halen günümüzde yoğun bir şekilde rotalama amaciyla kullanılmakta olan bir algoritmadır. Bu çalışmada, EYKAS mevcut çalışma alanı ve veri şartları dikkate alınarak HÇPP'ye yeniden uyarlanmıştır. Başlangıç düğümünden yola çıkan araç, hiyerarşiye bağlı kalarak, kendisine en k1sa mesafeli noktaları ziyaret ederek turu tamamlamaktadır.

Matlab programlama dili kullanılarak geliştirilen algoritmanın adımları Algoritma 1'de, yönteme ilişkin akış diyagramı da Şekil 4'te verilmiştir. Geliştirilen algoritmada, tanımlı olan bir başlangıç noktasından tura başlayan araç, ilk olarak 1. hiyerarşideki tüm yol ağ 1 kümesini kendisine en yakın noktaları takip ederek tamamlamaktadır.

Daha sonra, 1. hiyerarşi ile 2. hiyerarşiye ait ortak bir noktadan, sonraki hiyerarşik yol ağına geçilmekte ve bu ağdaki tüm yollar da en kısa mesafeli noktaları ziyaret ederek taranmaktadır. Tüm hiyerarşilere ait ağ üzerinde ziyaret edilmemiş yol kalmadığında araç, bulunulan noktadan başlangıç noktasına dönmektedir.

Algoritma 1. Geliştirilen sezgisel algoritma adımları

$$
i, j \in V
$$

$E_{h}=h$. hiyerarşik sınıfa ait yollar kümesi, $h=1,2, \ldots, \mathrm{H}$.

$h=1$.

$\mathrm{R}^{h}=\operatorname{rota},\left(\mathrm{R}^{h}(1)=1\right.$, başlangıç noktasi $)$

$\underline{\operatorname{Adlm} 1}$

For $t=2$ : tahmini rota uzunluğu

$\mathrm{S} \longleftarrow \mathrm{R}^{h}(t-1)$ düğümünden gidilebilecek tüm yollar kümesi, $\forall(i, j) \in E_{h}, h=1, \ldots, h$. $i=\mathrm{R}^{h}(t-1)$.

$\mathrm{HS} \longleftarrow \mathrm{R}^{h}(t-1)$ dügümünden gidilebilecek, daha önce hiç geçilmemiş yollar kümesi, $\forall(i, j) \in E_{h}, \mathrm{HS} \subseteq E_{h}, h=1, \ldots, h . i=\mathrm{R}^{h}(t-1)$.

if $\mathrm{HS} \neq[]$

$\mathrm{c}(i, j)$ hesapla, $\forall(i, j) \in$ HS için min $(i, j)$ belirle,

$\mathrm{R}^{h}(\mathrm{t}) \longleftarrow j$ dügümünü ata

elseif $\mathrm{HS}=\varnothing$

Hic_Alt=[ ], dizi setini oluştur. Zira HS= $\varnothing$ olduğu için S dizisinden atama yapılır. Ancak $S$ dizisindeki yollardan daha önceden geçildiği için atama random yerine şu şekilde yapılır. $\forall(i, j) \in \mathrm{S}$ dizisindeki her $j$. elemanın bağlantılı olduğu diğer yollara bakılır. Bu yollar arasından daha önceden hiç geçilmemiş $h$. hiyerarşik sınıfa ait yollar varsa, bu yollar Hic_Alt dizi setine dahil edilir. Dolayısıyla, mevcut düğümden gidilecek dügüm belirlenirken, gidilecek düğümün de bağlantılarına ve daha önceden geçilip geçilmediğine bakılarak karar verilir.

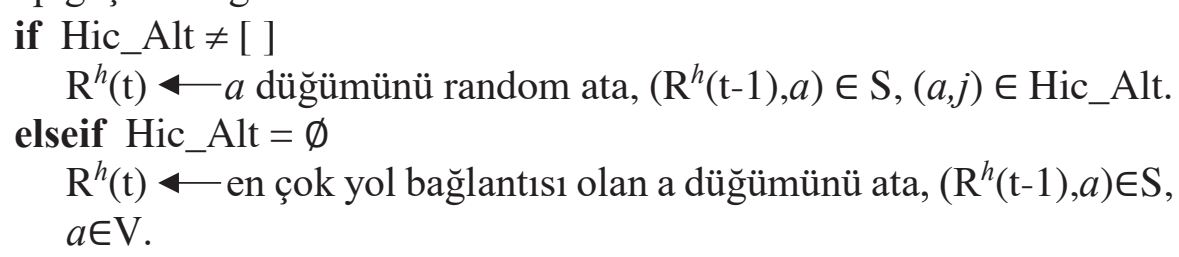



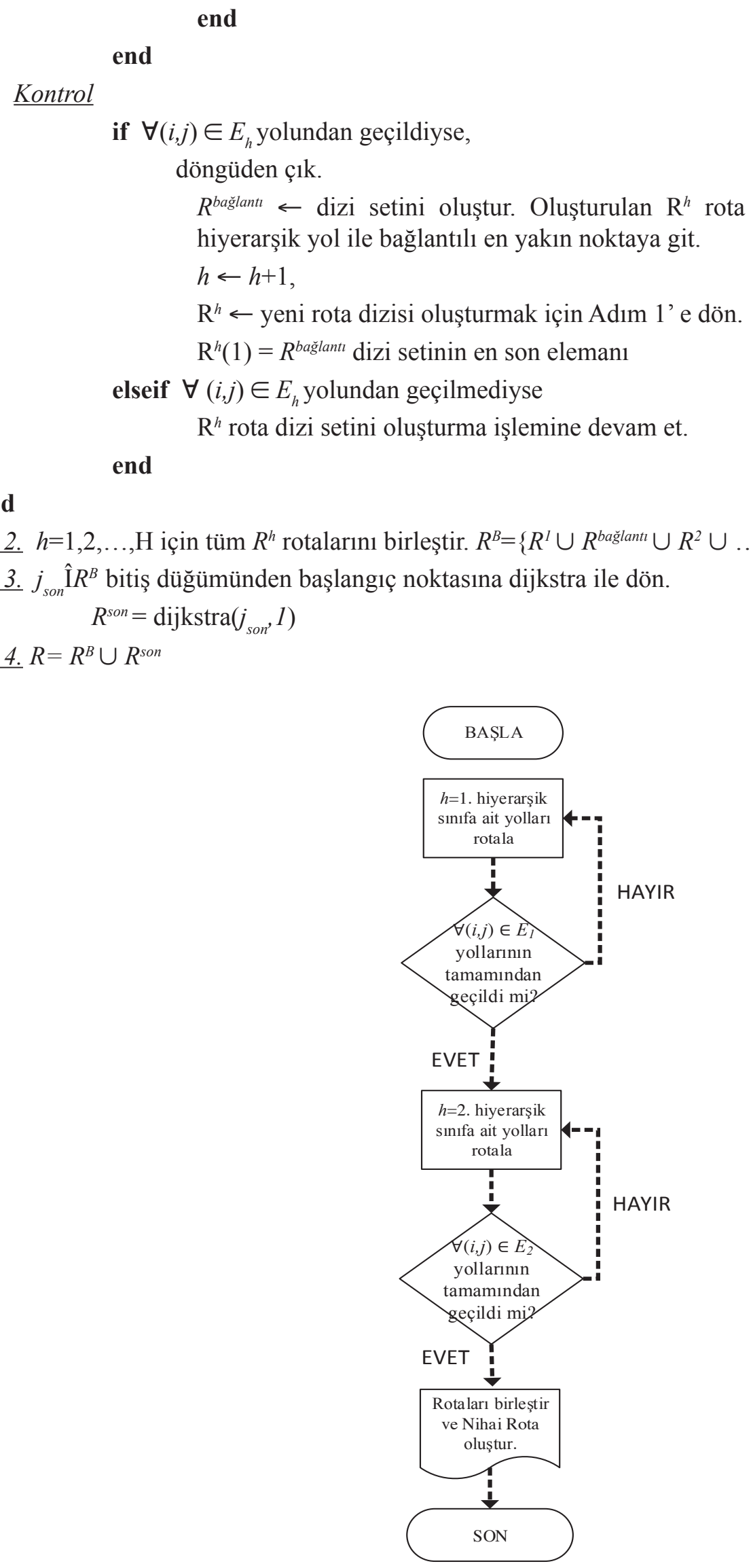

Şekil 4. Sezgisel algoritma akış diyagramı 


\section{BULGULAR VE TARTIŞMA}

$\mathrm{Bu}$ çalışmada Karayolları 12. Bölge Müdürlüğü görev alanındaki yolların bakım çalışmaları için mevcut durum incelenerek en iyi/en iyiye yakın rotayı bulmayı amaçlayan bir sezgisel algoritma önerilmiştir. Önerilen algoritma ile ele alınan yol hatlarının bakımında kat edilen toplam mesafenin minimize edilmesi amaçlanmıştır. Problem çözümünde Matlab 2016a programı, Intel i7 $3.40 \mathrm{GHz}$ işlemci $8 \mathrm{~GB}$ belleğe sahip bilgisayar kullanılarak sonuçlar elde edilmiştir.

Algoritma 500 döngü için çalıştırılarak elde edilen en iyi araç rotası ve kat ettiği mesafe Çizelge 1'de verilmiştir. Aracın ilk hareket noktası 1 numaralı düğüm olup turu tamamlayan araç tekrar başlangıç noktasına geri dönmektedir.

Çizelge 1. Sezgisel algoritma ile bulunan yerel en iyi rota

\begin{tabular}{|c|c|c|c|}
\hline Hiyerarşi no & $\mathbf{R}^{\mathbf{h}}$ & Yerel en iyi & $\begin{array}{l}\text { Kat edilen toplam } \\
\text { mesafe }(\mathbf{k m})\end{array}$ \\
\hline$h=1$ & $\mathrm{R}^{1}$ & $\begin{array}{l}1-8-7-6-5-2-1-5-6-68-73-74-73-11-12-11-10-11-73-68-67-68-6-7-71- \\
70-59-70-71-7-8-13-14-44-45-46-45-47-45-44-42-43-42-29-28-31-28- \\
30-32-33-32-34-36-38-39-38-40-38-41-38-36-37-36-34-35-34-32-30- \\
75-29-75-26-27-26-24\end{array}$ & 1439 \\
\hline bağlantı & $\mathrm{R}^{\text {bağlantı }}$ & - & - \\
\hline$h=2$ & $\mathrm{R}^{2}$ & $\begin{array}{l}24-25-24-23-15-14-15-16-9-8-9-3-2-3-4-3-10-3-9-16-17-18-19-18-20- \\
18-17-21-22-21-23-15-14-13-72-71-72-57-70-57-54-52-53-52-49-48- \\
49-50-51-50-52-54-55-56-55-58-59-60-61-60-62-69-62-63-66-65-64- \\
63-66-67-62\end{array}$ & 2152 \\
\hline dönüş & $\mathrm{R}^{\text {dönüş }}$ & $62-67-68-6-5-1$ & 109 \\
\hline $\begin{array}{l}\text { Toplam Rota }=\left\{\mathrm{R}^{1}\right. \\
\cup \mathrm{R}^{\text {bağlantı }} \cup \mathrm{R}^{2} \cup \\
\left.\mathrm{R}^{\text {dönüs }}\right\}\end{array}$ & & & 3700 \\
\hline
\end{tabular}

Çizelge 1'de görüldüğü üzere sunulan $\mathrm{R}^{1}$ rotas1 1 numaralı düğümden başlayıp sadece 1 . hiyerarşik yolları ziyaret etmektedir. Toplam kat ettiği mesafe 1439 km'dir. 1. hiyerarşik yolların tamamından geçildikten sonra, $\mathrm{R}^{1}$ rotasının 24 numaralı en son düğ̈̈mü 2 . hiyerarşik yol ile bağlantılı olduğu için $\mathrm{R}^{\text {bağlantı }}$ rotasına gerek kalmamıştır. 24 numaralı dügüumden itibaren tüm 2. hiyerarşik yolların geçildiği $\mathrm{R}^{2}$ rotasında kat edilen toplam mesafe ise $2152 \mathrm{~km}$ 'dir. $h$. hiyerarşik yoldan geçilirken; $(h-1),(h-2), \ldots, 1$. hiyerarşik yollardan geçilmeme şartı yoktur. Dolayısıyla $\mathrm{R}^{2}$ rotasında turu tamamlayabilmek için zaman zaman 1. hiyerarşik yollardan da geçildiği görülmektedir. Tüm yollardan geçilerek turun tamamlandığ 162 numaralı düğümden 1 numaralı başlangıç dügümüne en kısa mesafede geri dönüş yapılır. Böylece aracın hiyerarşik kısıtlar altında genel rotası $\mathrm{R}=\left\{\mathrm{R}^{1} \cup \mathrm{R}^{\text {bağlantı }} \cup \mathrm{R}^{2} \cup \mathrm{R}^{\text {dönüss }}\right\}$ şeklinde sağlanır. Toplam kat edilen mesafe 3700 km'dir.

Yapılan rotalama çalışması ile aracın yollardaki gereksiz tekrarlarından kaçınılmıştır. Ayrıca, yolların hiyerarşisi ile gerçek hayatta daha sık kullanılan, trafiğin yoğun olduğu alanlardaki bakım işleminin önce yapılması sağlanmıştır. Bu durum; güvenli ve etkin bir ulaşım sistemi için önemli bir yaklaşımdır.

\section{SONUÇ}

Rotalama birçok üretim ve servis sektöründe olduğu kadar ulaşım sektöründe de önemli bir karar verme sürecidir. Yerel yönetimler ve karar vericiler tarafından bu işlemler için her yıl büyük bir bütçe ayrılmaktadır. Bunun yanında hatalı planlamalar yüzünden bu bütçeler israf olmaktadır. Bu anlamda bu konuda yapılan çalışmalar çok büyük önem arz etmektedir.

Bu çalışmada, Karayolları 12. Bölge Müdürlüğü görev alanında bulunan yollarda kullanılan bir bakım aracının yönsüz yollar üzerinde en kısa uzunluktaki rotasının belirlenmesi ele alınmıştır. Ele alınan problem ayrit rotalama problemlerinden biri olan Hiyerarşik 
Çinli Postacı Problemi yöntemiyle çözülmüştür. Elde edilen sonuçlara göre pratikteki uygulamada aracın şebekeyi tamamlaması için birçok kez tekrar ettiği yollar bulunan yerel optimum rotada en kisa mesafede turun tamamlanması sağlanmıştır.

$\mathrm{Bu}$ çalışma bu yönüyle daha sonra yapılacak çalışmalara yol gösterici nitelikte olacaktır. Bakım aracının birden fazla olması, aracın belirli kapasiteye sahip olması veya rotalamanın zaman-bağımlı kısıtları

\section{KAYNAKLAR}

Alfa AS, Liu DQ, 1988. Postman routing problem in a hierarchical network. Engineering Optimization, 14: 127-138.

Ahuja RK, Magnanti TL, Orlin JB, 1993. Network Flows: Theory, Algorithms and Applications. Prentice Hall: New Jersey.

Cabral EA, Gendreau M, Ghiani G, Laporte G, 2004. Solving the hierarchical Chinese postman problem as a rural postman problem. European Journal of Operational Research, 155 (2): 44-50.

Clark PJ, Evans FC, 1954. Distance to Nearest Neighbor as a Measure of Spatial Relationships in Populations, 35 (4): 445-453.

Damodaran P, 1997. A methodology for dynamic planning of road service during a snow fall, Northern Illinois University, DeKalb, IL, M.S. Thesis.

Damodaran P, Krishnamurthi M, Srihari K, 2008. Lower Bounds For Hierarchial Chinese Postman Problem. International Journal of Industrial Engineering, 15 (1): 36-44.

Dror M, Stern H, Trudeau P, 1987. Postman tour on a graph with precedence relation on arcs. Networks, 17: 283-294.

Emel GG, Taşkın Ç, Dinç E, 2003. Yönsüz Çinli Postacı Problemi: Polis Devriye Araçları İçin Bir Uygulama. Anadolu Üniversitesi Sosyal Bilimler Dergisi, 3 (1): 121-140.

Ghiani G, Improta G, 2000. An algorithm for the hierarchical Chinese postman problem. Operations Research Letters, 26: 27-32. altında yapılması gibi varsayımlar altında problemin tekrardan ele alınarak çözüm yolları araştırılabilir. Daha önceden bahsedildiği gibi problem yapısı büyük boyutlu olup kompleks bir yapıya sahip olduğundan binlerce alternatif rota içerisinden en iyi/ en iyiye yakın rotanın bulunması zorluk teşkil edecektir. Bu nedenle, şebeke yapısı daha büyük daha karmaşık sistemler için uygun çözümler üreten diğer sezgisel/meta-sezgisel yöntemler geliştirilebilir.

Krishnamurthi M, Damodaran P, 1998. A modified postman tour heuristic for efficient snow removal planning, Proceedings of 7th Industrial Engineering Research Conference, Banff, Canada.

Korteweg P, Volgenant T, 2006. On the Hierarchical Chinese Postman Problem with Linear Ordered Classes. European Journal of Operational Research, 169: 41-52.

Kwan MK, 1962. Chinese Postman Problem, Graphic Programming Using Odd or Even Points, Chinese Math., 1: 273-277.

Lemieux PF, Campagna L, 1984. The snow ploughing problem solved by a graph theory algorithm. Civil Engineering Systems, 1: 337-341.

Sayata UB, Desai NP, 2015. An Algorithm for Hierarchical Chinese Postman Problem Using Minimum Spanning Tree Approach Based on Kruskal's Algorithm. 2015 IEEE International Advance Computing Conference, June 12-13, pp: 222-227.

Thimbleby H, 2002. Explaining Code For Publication, Software-Practice \& Experience.

Yılmaz M, Kayacı Çodur M, Yılmaz H, 2017. Chinese Postman Problem Approach for a Large-scale Conventional Rail Network in Turkey. Tehnicki Vjesnik-Technical Gazette, 5: 1471-1477. 